\title{
Teaching Research Methodology Using A Project-Based Three Course Sequence Critical Reflections On Practice
}

Kay H. Braguglia, Hampton University, USA

Kanata A. Jackson, Hampton University, USA

\begin{abstract}
This article presents a reflective analysis of teaching research methodology through a three course sequence using a project-based approach. The authors reflect critically on their experiences in teaching research methods courses in an undergraduate business management program. The introduction of a range of specific techniques including student developed research projects, student-centered learning experiences, and public presentation of research projects are reflected upon. In 2001, the Department of Management reviewed the curriculum and established a research sequence linking major management course offerings. Three courses: Statistics, Research Methodology and Organizational Behavior were selected to be taught in sequence and designed to build research expertise. This article addresses the processes, procedures and practices for implementing and sustaining an undergraduate research sequence. Techniques are included for course design, development, and facilitation that emphasize product based learning strategies and interactive elements. Techniques for garnering student engagement and excitement for research projects will be presented.
\end{abstract}

Keywords: Research Methods; Project Based Learning; Three Course Sequence

\section{INTRODUCTION}

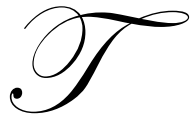

he information explosion has brought with it technological innovations that have changed classroom instruction and professor-student interactions and relationships. Students must know not only how to access readily available information but how to organize and make sense of the data. They must be able to decipher fact from fiction. Research methodology plays an important role in finding solutions to real world problems and the discovery of truth. Research skills also help to prepare undergraduate students for graduate level work.

In 2001, the Department of Management reviewed the curriculum and established a research sequence linking major management course offerings. Three courses: Statistics, Research Methodology and Organizational Behavior were selected to be taught in sequence and designed to build research expertise. This article involves a discussion of the processes, procedures and practices for implementing and sustaining an undergraduate research sequence. Techniques are included for course design, development and facilitation that emphasize product based learning strategies and interactive elements. Techniques for garnering student engagement and excitement for research projects will be discussed.

\section{TEACHING RESEARCH METHODS}

Learning about and doing research has value far beyond merely satisfying a program requirement. Research methods and their application to real-world problems are skills that serve students for the rest of their lives. The world is full of problems that beg for solutions. Therefore, it is full of research activity. Research activity is vital to the discovery of truth and to learn what has never been known before. To ask a question for which no 
conclusive answer has previously been found, and to collect and interpret relevant data to find an answer to that question can be exciting and rewarding. Research methodology can be applied to daily problems to demand a thoughtful solution. When a student learns to analyze problems systematically and dispassionately they have an opportunity for greater success and confidence (Leedy, 2010, p xvi). While those with research expertise may value research methods, students often look more for a quick answer to a problem and view research methods in a different light.

Research methods courses are becoming increasingly popular in degree requirements (Crooks, Castleden \& VanMeerveld, 2010). However, limited attention has been paid to the inherent challenges in running these courses which are often thought of as difficult to teach and resource (Crooks, Castleden \& Meerveld, 2010). Research methods courses are challenging classes to teach because the technical complexity of the course material is quite high while student interest in this material can be quite low (Ball \& Pelco, 2006). Students often complain that research methods courses are boring, inaccessible, or irrelevant to their everyday lives. Since students report anxiety related to research methods courses, teaching tracks that integrate research methods with other courses are recommended (Dion, Coxe, \& Carne, 2011).

\section{Project Based Approach}

Most research on Project-based Learning (PBL) has taken place during the last twenty years starting in the 1990's (Thomas, 2000). Project-based learning is a model that organizes learning around projects. According to most authors, projects are complex tasks, based on challenging questions or problems, that involve students in design, problem-solving, decision making, or investigative activities, provide students the opportunity to work relatively autonomously over extended periods of time; and culminate in realistic products or presentations (Jones, Rasmussen \& Moffitt, 1997). Other features include authentic content, teacher facilitation but not direction, and explicit educational goals (Moursund, 1999).

\section{Student-Centered Model}

The student-centered model can be modified through formal presentations of technical material and disciplinary insights to assist in student comprehension of complex material. In this model, the class time is taken up with 20 or 30 minutes of formal presentation followed by informal sessions using concrete examples and group exercises. In the context of teaching research methods, a combination of student centered and more traditional approaches to teaching is a recipe for success (Barraket, 2005). Even though the approach uses formal presentation of technical material and insights by the instructor, it is important to include hands on practice to transfer information. Any instructor who relies on a teaching approach based solely on a passive text-lecture-exam format runs the risk of driving student motivation and interest lower (Ball \& Pelco, (2006).

Traditionally taught lecture courses offer wider coverage of material but the group-project approach ensures a deeper understanding of the research process. Learning to do research and to critically evaluate research practices are better facilitated by problem solving than by memorizing research terms and definitions (Ball \& Pelco, 2006).

\section{THREE COURSE SEQUENCE}

\section{Course \#1 Statistics MGT 215}

A course in basic statistics is required as part of the core requirements for a degree in business. The course covers both descriptive and inferential statistics. This is a background course for the research sequence in the department.

\section{Course \#2 Research Methodology MGT 300}

The primary learning objectives in the Research Methodology Course are to develop students' critical and reflective thinking and practical skills in designing an empirical research proposal relating to business management. 
The course is taught to undergraduate business management students each semester during the academic year. The course schedule consists of two seventy-five minute sessions a week during a 15-week semester. Students are typically in their third year of undergraduate studies and have completed a course in statistics. The class enrollment is limited to 25 students. Most of the students are taking the course as a requirement for graduation in business management.

There are several practical and pedagogical challenges to teaching research methodology. The well known and primary challenge is how to make research methods interesting to students. The method employed to meet this challenge is to move away from a didactic teacher centered approach of transferring information about research methodology to the creation of an interactive environment where students master technical information through experience, reflection, and critical analysis. In this course, students design, develop and present a research proposal. The students work in groups of three. This project provides an active learning experience where students learn firsthand the challenges of selecting a topic, reviewing relevant literature, developing a hypothesis, choosing a research design, plan for collection of data, and choosing the statistical analysis. These methodical decisions are more meaningful when applied to problems students have identified rather than straight instructor-led class with tests over a textbook.

Students perform well when given specific guidelines as to the proposal requirements. An outline of the proposal requirements is provided as part of the syllabus. A set of specific requirements are listed on an additional sheet. These learning aids or scaffolding are intended to help students become proficient in conducting research inquiry activities. According to Thomas (2000) an instructor should scaffold instruction by breaking down tasks, use a model to prompt and coach helping the student to think and solve the problem and gradually release responsibility to the learner. This type of instruction is more flexible than didactic teaching methods and yields knowledge and skills that are more likely to be retained. Access to all learning aids is placed on Blackboard, the university on line assistant. Students are able to download tips, outlines, and directions.

The type of activities involved in methodology varies considerably from one research design to the next. Therefore, the course requirements are to use a quantitative research design selected from a choice of five: survey, observational, correlation, quasi experimental, or experimental. The course also requires the use of a probability sampling procedure and the students must choose from simple random, cluster, systematic, or stratified. Narrowing the choices allows for uniform grading procedure and provides a framework for undergraduate students.

\section{Five Phases of Student-group Proposals}

Phase 1: Research Problem

During the first phase the instructor introduces the selection of an appropriate research topic. The student groups brainstorm generating ideas for a topic. After each group selects a business related topic, they search for at least five journal articles related to the topic. This topic is turned in to the instructor and discussed with each group. Students refine their ideas and limit their topic to one that can be completed in the time of the course. The next three class periods involve an instructor led discussion for 30 minutes followed by a group meeting where students formulate and write a draft of the first section of their proposal. The first section includes a statement of the problem, a research hypothesis, definition of terms, and importance of the study. This section is turned in to the instructor the fourth week of class in draft form. It is reviewed and discussed with each group. The instructor interacts frequently with each group to facilitate and guide key decisions.

\section{Phase 2: Literature Review and Ethics Discussion}

Once the research problem is chosen and approved by the instructor, students review the relevant literature of published research on their topic. The instructor leads a discussion on library resources and data bases, and determining quality sources. Students turn in a practice assignment demonstrating their knowledge of the American Psychological Association (APA) format. After an investigation of previous research, students write a short literature review using (APA) format. This draft is turned in to the instructor for suggestions for improvement. 
A discussion of ethics in research including the need for a statement of informed consent and the role of the Institutional Review Board (IRB) is included in this phase. History of abuses in research and current issues are presented. In class, students evaluate a mini case where questionable research was conducted.

Phase 3: Research Methodology

The methodology section is the most challenging for the students. It includes four sections: (1) research design, (2) selection of participants, (3) data analysis procedure, and (4) findings. It is important for the instructor to interact frequently with each group to facilitate and guide the decisions made in this section. It is very helpful for the instructor to provide formal instruction for each of these sections. This information is totally new to many undergraduate students. Therefore, a thirty minute lecture with PowerPoint slides is presented at the beginning of each section. The students are also provided handouts and aids with details of the requirements for each section. The students then meet in groups during the last 40 minutes of each class to make decisions about their project and receive assistance from the instructor. This step by step process provides for mastery of each task. Helpful items such as a statement of informed consent, letter of transmittal, and examples are provided on Blackboard. It is important for students to be able to apply what they learn to solve problems and make decisions.

Phase 4 Budget and Timeline

The last section of the proposal includes a budget, time line and qualifications of the researchers. Students usually complete this section with ease.

Phase 5: Proposal Presentation

The instructor provides information on the structure and requirements for the presentation. Each group presents their proposal to the class in a 20 minute presentation. Each group illustrates the major sections of their proposal on a poster. The presentations are organized and delivered to simulate a poster session at a conference. Each presentation is followed by a 10 minute question and answer period. Student groups are selected at random to evaluate both their own presentation and one other group. The students turn in a written proposal as a group after presenting their proposal to the class. Students evaluate the contribution of their group members on a form denoting the percentage of effort of each group member.

\section{Public Display Research Forum}

Each November, the Department of Management hosts a Business Research Forum where students present their proposals. The proposals are presented as a Poster Session where the students discuss their work with university faculty, students and staff. This Forum is attended by approximately 300 people each year and featured in the student newspaper. The Forum generates excitement and interest in research and is staged as a professional conference. Students take pride in their work and strive to produce high quality proposals. Many students use their research proposals as part of their capstone course for the Honors Program and several complete the research project and submit it to the journal published by the Management Department for publication.

\section{Summary of Research Methodology}

In review of the research methods course, assessment of the course results have shown that $90 \%$ of the students complete the proposal with a score of $80 \%$ or more on the project. In reflection, the research methodology course has several excellent features: (1) it is product-based and produces a quality proposal, (2) it is learner centered and intrinsically motivating, (3) it encourages collaboration and cooperative learning, (4) it allows for incremental and continual improvement in their product, (5) it is designed so that students are actively engaged in doing things rather than learning about things and (6) it is challenging and focuses on higher-order skills. With these quality attributes a few issues remain unresolved: it is time consuming to teach and requires personal attention to each group both inside and outside of class, and it requires timely grading and feedback at milestones as the project proceeds. 


\section{Course \#3 Organizational Behavior}

Organizational Behavior is the study of individual and group behavior within the context of the organizational workplace setting. It is an interdisciplinary field that traditionally includes sociology, psychology, communication, and management. Multiple frameworks are introduced to further students' understanding of the interactions and relationships in organizations on individual, group and the macro level of organizational systems.

Organizational Behavior is a required course for graduation and offered at the senior level. In this case, it also includes a comprehensive research study as part of the last course in the three course research sequence. Students are actively involved in a dedicated organizational research project resulting in contributions to the larger body of knowledge of organizational behavior. The following will be a discussion of the research component of this course which is completed in five stages.

Stage 1 - Selection of research topics

During the first day of class, the research study requirements are outlined. Each student is required to (1) select a topic from an approved list, (2) conduct a descriptive research project using survey methodology, (3) write a research article, and (4) submit the article for publication in The Collegiate Journal of Organizational Behavior, the student authored publication of the Organizational Behavior course.

\section{Stage 2 - Submission 1}

The requirements for the research project are the same for every student. Each student selects a topic from the approved list and conducts an extensive search for journal articles on the subject. Students are required to locate between 35 and 45 articles and present a list of them to the instructor for approval. The student then writes the theoretical framework for their research and a literature review using the American Psychological Association (APA) format. This is submitted to the instructor via email for comment and correction. The course is paperless with all drafts, corrections and feedback being exchanged electronically.

\section{Stage 3 - Submission II}

All students develop a questionnaire using a Likert scale and field test the instrument as an in class exercise. The finalized questionnaire is submitted with the second draft of the paper. The professor notifies students of approval to distribute final questionnaires. Students administer the questionnaire to select participants using a non-probability sampling procedure. The participants are often students or local business owners. However, in some cases the participants have been nationwide and a few times international in scope with participating universities from overseas. The results of the questionnaire are tabulated and analyzed using percentages. Outcomes are illustrated with pie charts or graphs. The students complete the research article with a discussion of their results and recommendations for further study.

\section{Stage 4 - Submission III}

The completed research paper is submitted and includes previous sections plus the methodology, statistical data analysis with graphs, charts, tables and narrative, conclusions and implications for further study.

\section{Stage 5 - Presentation of research study and journal preparation}

Each student shares the results of their research study with the class augmented by a PowerPoint presentation.

The finalized research article is submitted to the instructor. Once the papers are graded they are forwarded to a team of two-four students who serve as editors of The Collegiate Journal of Organizational Behavior. Student editors are selected each semester by the instructor. This assignment provides leadership development opportunities for those selected. After editing the articles, the students compile the journal into a professional bound journal and present the final volume for that semester to the instructor as the final product for the course. One copy of the journal is kept in the University library and another one is kept in the Department of Management Office. 


\section{Summary of Organizational Behavior}

A reflection on the Organizational Behavior course concludes that the students have an opportunity to develop, reinforce, and refine their research skills. Assessment of the course shows that $95 \%$ of the students earn a score of $80 \%$ or more on their research project. Students also practice decision making, report writing, and presentation of their work for critical review and publication. Drawbacks to the course are that it is time consuming to teach with feedback being required at crucial points in the process. Also, even though The Collegiate Journal of Organizational Behavior is in the library and management office, publication for the journal to a larger audience would increase its value.

\section{CONCLUSION}

In conclusion, the three course sequence builds research expertise among the students. Students report high levels of satisfaction with the courses, and the quality of the products they generate demonstrate a high level of student engagement and excitement with the concept of formal research. The success of students in the courses has brought recognition to the department and students in the Research Forum and journal publication. The products in the form of proposals and journal articles have been presented to departmental review boards and accreditation agencies. Several students after completing the sequence have utilized their research knowledge while participating in award-winning case studies throughout the United States. Others have returned to report the benefits of the program after enrolling in graduate school. A few students have found employment conducting research for companies and presently work in that capacity.

\section{AUTHOR INFORMATION}

Kay, H. Braguglia, Ed.D., Higher Education Administration, Ed.S., Human Resource Development, The George Washington University; M.S., B.S., University of Missouri at Columbia. Assistant Professor, Department of Management, Hampton University. Research includes factors that contribute to student success in college, including both student habits and college teaching methods, especially the use of technology, collaborative instruction, outcomes assessment and evaluation. E-mail: kay.braguglia@ hamptonu.edu

Kanata A. Jackson, Ph.D., Organizational Behavior, United States International University. Chair, Department of Management, Hampton University. Research includes the impact of policies, procedures and practices on highperformance employees, the contingent workforce, and diversity of international management practices. E-mail: kanata.jackson@hamptonu.edu

\section{REFERENCES}

1. Ball, C.T., \& Pelco, L.E. (2006). Teaching Research methods to undergraduate psychology students using an active cooperative learning approach. International Journal of Teaching and Learning in Higher Education, 17( 2), 147-154.

2. Barraket, J. (2005). Teaching research method using a student-centered approach? Critical Reflections on Practice. Journal of University Teaching and Learning Practice, 12(2). Article 3.

3. Crooks, V.A., Castleden, H., \& VanMeerveld, I.T. (2010). Teaching research methods courses in Human Geography: Critical Reflections. Journal of Higher Education, 34(2), 155-171.

4. Dion, M., Coxe, L.M., \& Carne, M. (2011). Track Four: Teaching Methods, The American Political Science Association, 34(2) 155-171.

5. Jones, B.F., Rasmussen, C.M., \& Moffitt, M.C. (1997). Real-life problem solving: A collaborative approach to interdisciplinary learning. Washington DC: American Psychological Association.

6. Leedy, P.D. \& Ormrod, J. E. (2010). Practical Research $\left(9^{\text {th }} e d\right)$. : Upper Saddle River, NJ: Pearson.

7. Moursund, D. (1999). Project-based learning using information technology. Eugene. OR: International Society for Technology in Education.

8. Thomas, J. (2000). A review of research on project-based learning. Retrieved September 12, 2011, http://www.autodesk.com/foundation 